\title{
Influence of yeasts of the genus Saccharomyces and not Saccharomyces in elaboration of white wines
}

\author{
L. Quincozes, P. Santos, L. Vieira, M. Gabbardo, D.P. Eckhardt, W. Cunha, V. Costa, L. Zigiotto, and R. Schumacher
}

Federal University of Pampa, Dom Pedrito, RS, Brazil

\begin{abstract}
Traditionally the Serra Gaúcha region, in the state of Rio Grande do Sul, is known as a barn productor of excellent quality wines. The aromatic complexity of wine in general, and white wine in particular, is what is essential to satisfy an increasingly demanding consumer. Among the most used techniques to achieve this purpose is the addition of yeasts of different genres, thus providing a range of aromatic characteristics that are accentuated in it. In this sense, the objective of this work was to evaluate the use of different strains of yeasts in white wines of Riesling Italic variety, made from grapes grown in the Serra Gaúcha region, in the state of Rio Grande do Sul. Based on the results, it was possible to observe that there were no significant differences between the treatments in relation to the variables $\mathrm{pH}$, total acidity and alcoholic degree. However, with respect to the fermentation yield, T3 was the treatment that obtained the best performance, reaching the ideal density (below $1000 \mathrm{~g} . \mathrm{cm}^{3}$ ) in the course of 6 to 7 days, followed by treatments T1 (Saccharomyces cerevisae) and T5 (Levulia pulcherrima) (7 to 8 days), with treatments T2 (Saccharomyces cerevisae cerevisae) and T4 (Torulaspora delbrueckii), which had the lowest performance ( 9 to 10 days). The T4 treatment was also the one that presented a higher amount of residual sugars, which proves the less activity of this yeast in more alcoholic means. All the yeasts used have a low production of volatile acidity, but the lowest concentration was Saccharomyces cerevisae cerevisae, used in treatment $\mathrm{T} 2\left(0.1 \mathrm{gL}^{-1}\right)$, and the other treatments presented higher concentrations $\left(0,4\right.$ to $\left.0.5 \mathrm{gL}^{-1}\right)$, although it is still within the parameters considered ideal for obtaining quality white wines. T2 was also the treatment with lower concentrations of glycerol $\left(5.1 \mathrm{~g} . \mathrm{L}^{-1}\right)$. This compound is mainly formed by glyceropyruvic fermentation through the metabolism of yeasts at the beginning of alcoholic fermentation, usually being produced by the first 50 grams of fermented sugars, which may indicate a greater activity of this yeast in this fermentation period. In general, we can say that all the yeasts used have the potential to produce quality white wines, since they had good fermentation yields, satisfactory production of alcohol and glycerol, and low production of volatile acidity.
\end{abstract}

\section{Introduction}

wine is the alcoholic beverage obtained from the fermentation of fresh, healthy and mature grape must by yeast, usually Saccharomyces cerevisiae [1]. Wine is extremely important to many people, from an economic point of view, but also by social, cultural, gastronomic and religious aspects. In addition, the literature indicates that wine consumption may promote some beneficial health effects, including protection against cardiovascular disease and Alzheimer's disease [2].

Riesling Italic is a Vitis vinifera variety that has been widely produced in the region of Serra Gaúcha / RS, used in the elaboration of fine white and sparkling wines. "Riesling Italic" grapes are characterized by small and compact bunches, intermediate maturation and regular sugar concentration potential in the berry. It has a slightly pronounced varietal aroma and usually promotes secondary aromas, enough to be classified as fruity wine [3].

The quality of the wine is dependent both on the quality of the grape must and on the evolution of the microbiota during the fermentation and vinification process [4]. The chemical composition of wines and their sensorial characteristics are strongly conditioned by the components released by the yeasts during alcoholic fermentation. Thus, the genetic and physiological variability of oenological yeasts will be decisive for technological and sensorial properties of wine [1].

There is a recent interest in the scientific community to seek new strategies to increase the complexity and distinctive characteristics of wines with a view to increasing added value. The fermentation processes and the controlled inoculation of different species of conventional yeasts (Saccharomyces genus) and nonconventional yeasts (not Saccharomyces) is a strategy to explore oenological characteristics that yeasts will promote in wine [5]. In this sense, the use of unconventional yeasts in wine fermentation becomes increasingly popular, particularly due to its effects on wine composition, taste, aroma and color [6,7].

The objective of this work was to evaluate the use of different strains of yeasts in white wines of the Riesling Italic variety, elaborated from grapes grown in the Serra Gaúcha region and characterize their physicochemical properties.

\section{Material y métodos}

The experiments were performed using $100 \mathrm{~L}$ of Riesling Italic, previously sulphited $\left(72 \mathrm{mg} . \mathrm{L}^{-1}\right.$ of $\left.\mathrm{SO}_{2}\right)$, from the 
Serra Gaúcha region (latitude $29^{\circ} \mathrm{S}$, longitude $51^{\circ} \mathrm{W}$, altitude $600-800 \mathrm{~m}$ ). The same was conditioned in a stainless steel tank for 24 hours, for the debourbage (process of decanting solid particles from the must). After the raking fermentation step was carried out and samples of the must were taken for physicochemical analyzes, such as: sugar $\left(\mathrm{gL}^{-1}\right)$, total soluble solids ( $\left.{ }^{\circ} \mathrm{Brix}\right), \mathrm{pH}$, total acidity $\left(\mathrm{gL}^{-1}\right)$, tartaric acid and gluconic acid. Subsequently, the GERFERM PLUS $\cap$ nutrient was added at a dosage of $25 \mathrm{~g} . \mathrm{hL}^{-1}$ and the chaptalization was performed by the addition of $18 \mathrm{~g} . \mathrm{L}^{-1}$ sucrose, with the aim of increasing the alcohol volume by $1.0 \%$. The must was then fractionated in $14 \mathrm{~L}$ bottles, distributed in five treatments, each with three replicates. Each treatment received the addition of a different yeast species. Yeasts were randomly assigned and inoculated at $3 \mathrm{~g} \cdot \mathrm{hL}^{-1}$ concentration per treatment. Three yeasts of the Saccharomyces genus were used. In Treatment 1 (T1) Saccharomyces cerevisae; in Treatment 2 (T2) Saccharomyces cerevisae cerevisae, and in Treatment 3 (T3), a Saccharomyces bayanus. In addition, two non-Saccharomyces yeasts were inoculated, being Torulaspora delbrueckii in Treatment 4 (T4) and Levulia pulcherrima in Treatment 5 (T5).

All treatments underwent alcoholic fermentation at a controlled temperature of $15^{\circ} \mathrm{C}$ for 10 days. During this period, temperature and density measurements were performed daily to accompany the fermentation. On the 3rd and 5th day of fermentation, $10 \mathrm{~g} \cdot \mathrm{hL}^{-1}$ of ACTIMAX VIT $R$ (fermentation activator) was added to each bottle. After the fermentation stage, the bottles were stored in a cold room at $8^{\circ} \mathrm{C}$ for 30 days, for tartaric stabilization. During the first 24 hours, a thick sediment was decanted and immediately transferred to $4.6 \mathrm{~L}$ bottles, where $40 \mathrm{mg} . \mathrm{L}^{-1}$ of $\mathrm{SO}_{2}$ was added to avoid malolactic fermentation and $0.09 \mathrm{gL}^{-1}$ bentonite for clarification. On the 12th day a new transfer was carried out to remove the bentonite. The bottles were kept in a cold chamber for subsequent packaging and sample withdrawal for the analytical determinations of the treatments. Analyzes of $\mathrm{pH}$, total acidity $\left(\mathrm{gL}^{-1}\right)$, volatile acidity $\left(\mathrm{gL}^{-1}\right)$, reducing sugar $\left(\mathrm{gL}^{-1}\right)$, alcohol $(\%, \mathrm{v} / \mathrm{v})$ and glycerol $\left(\mathrm{gL}^{-1}\right)$ were performed by WineScan ${ }^{\mathrm{TM}} \mathrm{SO}_{2}$ (FOSS), which analyzes the samples based on principles of infra-red vibrational spectroscopy.

\section{Results and discussion}

Table 1 presents the parameters related to the quality of the must used in the winemaking process. Based on the results, we can affirm that almost all the values were considered normal for grape variety Riesling Italic cultivated in the region of Serra Gaúcha.

The only parameter considered a little above the optimal values was gluconic acid. Gluconic acid is a product of the oxidation of the aldehyde function of glucose and its presence in grapes and wines is directly related to the effects of the fungus Botrytis cinerea, which in turn is influenced, among other factors, by the climatic conditions, mainly by the high indexes of humidity [8]. Although the gluconic acid content found in this work was higher than 1.0 g.L $\mathrm{L}^{-1}$, no interference in the vinification process and the sensorial quality of the wines was diagnosed.
Table 1. Physicochemical parameters of the must used in the vinification process.

\begin{tabular}{|c|c|}
\hline Variables & Averages \\
\hline Sugars $\left(\mathrm{g} . \mathrm{L}^{-1}\right.$ ) & 167.6 \\
\hline Total Soluble Solids $\left({ }^{\circ}\right.$ Brix $)$ & 17.1 \\
\hline $\mathrm{pH}$ & 3.5 \\
\hline Total Acidity $\left(\mathrm{g} . \mathrm{L}^{-1}\right)^{*}$ & 6.1 \\
\hline Tartaric Acid $\left(\mathrm{g} . \mathrm{L}^{-1}\right)$ & 5.1 \\
\hline Malic Acid $\left(\mathrm{g} . \mathrm{L}^{-1}\right)$ & 4.0 \\
\hline Gluconic Acid $\left(\mathrm{g} . \mathrm{L}^{-1}\right)$ & 1.4 \\
\hline
\end{tabular}

*Tartaric Acid
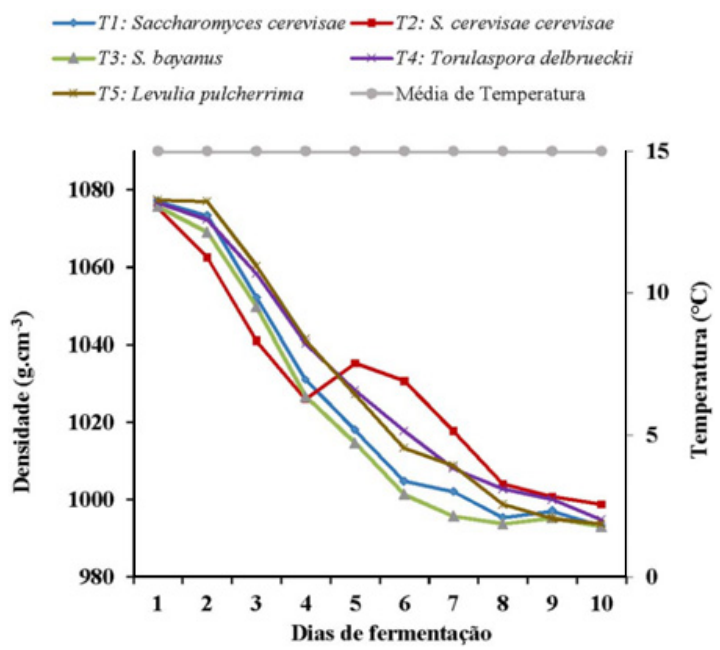

Figure 1. Monitoring of the density during the fermentation of the Riesling Italic must by different yeasts.

Figure 1 shows the yields of alcoholic fermentation of the different treatments. It was observed that T3, inoculated with strain Saccharomyces bayanus, was the treatment that obtained the best performance, arriving at the ideal density (below $1000 \mathrm{~g} . \mathrm{cm}^{-3}$ ) in the course of 6 to 7 days, followed by T1 treatments (Saccharomyces cerevisae ) and T5 (Levulia pulcherrima) after 7 to 8 days, respectively. Treatments T2 (Saccharomyces cerevisae cerevisae) and T4 (Torulaspora delbrueckii) presented slower performance ( 9 to 10 days). However, the inherent behavior of the respective yeasts, even if late, did not prevent them from reaching the desired alcoholic strength.

The highest fermentation yield for T3 (Saccharomyces bayanus) was expected, since this yeast strain has as main characteristic the fast fermentation and good tolerance to higher concentrations of alcohol [9]. Another yeast that obtained good fermentation yield was Levulia pulcherrima. The literature presents a variability of results on the yield of fermentations of this yeast. While some authors have found good results [10], others suggest that this yeast has low fermetation kinetics, as well as low resistance to sulfur dioxide (SO2) and alcohol $[5,11,12]$. On the other hand, the yeast Torulaspora delbrueckii (T4), had one of the worst performances, corroborating with the results found in previous studies, when its use is indicated for simultaneous fermentations with strains of Saccharomyces yeasts to obtain better fermentative yields $[13,14]$.

Table 2 shows the physical-chemical parameters, including the alcohol content, of the wines produced with the different yeasts. Treatment with yeast Saccharomyces 
Table 2. Analysis of the conventional parameters in wines from the different treatments with yeast strains.

\begin{tabular}{|l|c|c|c|c|c|c|}
\hline \multirow{2}{*}{ Analysis } & \multicolumn{5}{|c|}{ Treatments } & \multirow{2}{*}{ CV (\%) } \\
\cline { 2 - 6 } & T1 & T2 & T3 & T4 & T5 & \\
\hline Alcohol & $10.63^{\mathrm{b}}$ & $10.69^{\mathrm{a}}$ & $10.54^{\mathrm{c}}$ & $10.49^{\mathrm{d}}$ & $10.61^{\mathrm{b}}$ & 0.35 \\
\hline Residual Sugar & $1.02^{\mathrm{bc}}$ & $0.93^{\mathrm{c}}$ & $1.03^{\mathrm{bc}}$ & $3.50^{\mathrm{a}}$ & $1.11^{\mathrm{b}}$ & 7.93 \\
\hline Glyceroll & $6.01^{\mathrm{c}}$ & $5.09^{\mathrm{d}}$ & $6.34^{\mathrm{a}}$ & $6.24^{\mathrm{b}}$ & $5.99^{\mathrm{c}}$ & 1.23 \\
\hline pH & $3.36^{\mathrm{b}}$ & $3.30^{\mathrm{c}}$ & $3.37^{\mathrm{a}}$ & $3.36^{\mathrm{b}}$ & $3.36^{\mathrm{b}}$ & 0.13 \\
\hline Malic Acid & $2.51^{\mathrm{a}}$ & $2.54^{\mathrm{ab}}$ & $2.57^{\mathrm{a}}$ & $2.38^{\mathrm{c}}$ & $2.57^{\mathrm{a}}$ & 1.56 \\
\hline Latic Acid & $0.10^{\mathrm{b}}$ & $0.01^{\mathrm{c}}$ & $0.12^{\mathrm{b}}$ & $0.34^{\mathrm{a}}$ & $0.10^{\mathrm{b}}$ & 30.23 \\
\hline Total Acidity & $6.63^{\mathrm{c}}$ & $6.40^{\mathrm{d}}$ & $6.65^{\mathrm{c}}$ & $6.71^{\mathrm{b}}$ & $6.83^{\mathrm{a}}$ & 0.74 \\
\hline Volatile Acidity & $040^{\mathrm{c}}$ & $0.10^{\mathrm{d}}$ & $0.40^{\mathrm{c}}$ & $0.42^{\mathrm{b}}$ & $0.50^{\mathrm{a}}$ & 4.86 \\
\hline
\end{tabular}

* Different letters on the same line indicate a statistically significant difference by the Tukey test at $5 \%$. Alcohol (\% v.v); Residual sugar (g.L $\left.{ }^{-1}\right)$, Glycerol (g.L $\left.{ }^{-1}\right)$,

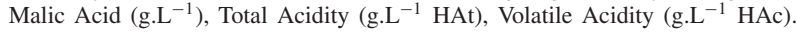
T1: Saccharomyces cerevisae; T2: Saccharomyces cerevisae cerevisae; T3: Saccharomyces bayanus; T4: Torulaspora delbrueckii; T5: Levulia pulcherrima.

cerevisae cerevisae (T2) presented the highest alcohol content. It should be noted that, although there is a significant statistical difference, the concentration of ethanol produced by the yeast Levulia pulcherrima (T5) was very close to the yields obtained by yeasts of the genus Saccharomyces (T1, T2, T3), which are normally used for the production of wine, evidencing that this strain of yeast has potential to be used in a monoculture system for the production of white wines. These results are in agreement with those found by Sadoudi et al. (2012) [15], however, are different from those reported by Comitini et al. (2011) [5], both developed in mixed fermentations with Saccharomyces. The alcohol content of the wine fermented with T. delbrueckii (T4) was the lowest among the treatments. Several authors argue about the usefulness of this non-Saccharomyces yeast in the production of lower alcohol concentrations in wines, with reductions of more than $1 \%$ in the final alcohol content $[16,17]$. However, in the present study, the reduction of ethanol levels was lower than $0.2 \%$, a result similar to that found by Breda et al. (2015) [14]. In general, it was observed that all treatments presented satisfactory results regarding the conversion of sugar into ethanol. Brazilian legislation establishes for fine white wines from 8.6 to $14.5 \%$ (v.v) [18], with all treatments falling within this range. Alcohol, in addition to being directly related to the organoleptic qualities of wines, also has an antiseptic property that, along with acidity, can prolong the preservation and prevent undesirable changes in wines [8].

Regarding the residual sugar contents, T4 (Torulaspora delbrueckii) was the one with the highest value. This result may be related to the lower production of ethanol by this yeast described previously. Some authors report a lower fermentative power of Torulaspora delbrueckii compared to strains of Saccharomyces cerevisae, mainly in the final stages of fermentation, due to the high nutrient demand of these yeasts (Torulaspora delbrueckii) [13]. To improve the residual sugar consumption, this yeast should be inoculated in cultures with sequences of Saccharomyces cerevisae yeast strains. However, all treatments are in accordance with the limits established by Brazilian legislation, which for residual sugar, of dry white fine wines, is at most $4 \mathrm{~g} . \mathrm{L}^{-1}$ [18].

The production of glycerol is affected by sugar concentration, fermentation temperature, $\mathrm{pH}$, yeast strain and amount of oxygen present [19]. The treatment with S. Bayanus (T3) promoted a highly active route of glyceropyruvic fermentation, evidenced by the higher glycerol content among the treatments. According to the literature, several species of Saccharomyces yeasts can produce from 2 to 10 g. $\mathrm{L}^{-1}$ of glycerol. Cryotolerant species such as $S$. Bayanus ( $S$. uvarum) are those that produce above-average glycerol [9]. Torulaspora delbrueckii (T4) was the strain that promoted the second highest glycerol content among the treatments studied, and similar results were found by Comitini et al. (2011) [5]. The T2 treatment, which used yeast Saccharomyces cerevisae cerevisae, had the lowest concentration of glycerol $\left(5.1 \mathrm{~g} . \mathrm{L}^{-1}\right)$. It is believed that this lower production of glycerol in $\mathrm{T} 2$ was caused by a possible yeast injury, which occurred on the 5th day of fermentation (Graph 1). According to Swiegers et al. (2005) [1], glycerol is present in dry and semi-sweet wines in concentrations ranging from 5 to 14 g. $\mathrm{L}^{-1}$. Although the concentration of glycerol has no direct impact on the aromatic characteristics of wine, it can have a remarkable effect on sweetness and sensation in the mouth, called "wine body" [20].

The $\mathrm{pH}$ values found in all treatments of this study remained within the range considered optimal for the production of quality white wines (3.0-3.8). Knowledge of $\mathrm{pH}$ in wines is extremely relevant, as it may influence the physical-chemical stability of the wine and its resistance to microbial contaminations. The wine becomes more susceptible to attacks when the $\mathrm{pH}$ is above 3.5 , requiring the microbiological control of the same, because the microbiota develops easily in the medium $[8,21]$.

Total acidity is a key parameter for wine quality. In its determination all the types of acids present are quantified. The acid profile is derived from the grape itself and can also be formed during the fermentation, depending on the yeasts used and the ripeness of the wine [5]. In this study, the highest concentrations of total acidity were found in the treatments using non-Saccharomyces yeasts. The highest concentrations are related to yeast Levulia pulcherrima (T5) and Torulaspora delbrueckii (T4), respectively. These results are in agreement with those reported by some authors. Contini et al. (2011) [5], indicate a decrease in total acidity and $\mathrm{pH}$ levels when concomitant use of yeast type Levulia pulcherrima and Saccharomyces cereviseae. Belda et al. (2015) [13] found lower total acidity in wines inoculated with yeasts of the Torulaspora delbrueckii type compared to wines fermented with yeasts of the genus Saccharomyces. This effect on total acidity in white wines can be both positive and negative, depending on the type of product being prepared. Generally, higher acidity is beneficial for dry white wines, because in addition to interfering with color and aroma, they confer resistance to oxidation processes [22]. Despite the variations among the treatments, all wines presented total acidity levels within the standards (maximum of $9.75 \mathrm{~g} . \mathrm{L}^{-1}$ of tartaric acid) indicated for fine wines in Brazilian legislation [18].

The highest levels of total acidity in the treatment with Levulia pulcherrima (T5) may be related to the higher levels of malic acid found in these treatments (Table 2). However, this condition is not valid for the treatment inoculated with Torulaspora delbrueckii (T4), which despite having a higher acidity, was the treatment that presented the highest consumption of malic acid. Larger amounts of malic acid by this yeast, compared to the Saccharomyces genera, were also reported by $[13,23]$. However, this consumption was very small 
because lactic acid concentrations showed absence of malolactic fermentation, which confirms that there was no contamination by lactic acid bacteria in any of the treatments studied.

The concentrations of volatile acidity in wines were similar for most of the yeasts used $\left(0.4\right.$ to 0.5 g.L $\left.\mathrm{L}^{-1}\right)$. Only the strain Saccharomyces cerevisae cerevisae (T2) produced lower levels $\left(0.10 \mathrm{~g} . \mathrm{L}^{-1}\right)$. The high production of acetic acid by yeasts of the non-Saccharomyces genus has been reported as one of the obstacles to the use of these strains in the alcoholic fermentation of wines [13]. However, more recent studies using these yeasts have demonstrated the production of volatile acidity equal to or less than those of the genus Saccharomyces [24-26]. The present work proves with these results, where the yeasts Torulaspora delbrueckii and Levulia pulcherrima produced levels of volatile acidity similar to the yeasts of the genus Saccharomyces. These levels probably do not affect the sensory quality of wines and are well below the maximum limits allowed by law [18].

\section{Conclusions}

The yeasts of the non-Saccharomyces genus present potential for the production of dried white wines of the Riesling Italic variety with similar quality to those produced by yeasts of the Saccharomyces type, as they demonstrate good yields of fermentation, satisfactory production of alcohol and glycerol, as well as low volatile acidity production.

More detailed studies are needed, especially regarding the profile of volatile compounds and the sensorial characteristics of the wines, which are already being developed by the research group.

\section{References}

[1] J. Swiegers, I. Pretorius, Appl. Microbiol. Biotechnol. 74, 954 (2007)

[2] N. Pirastu, M. Kooyman, M. Traglia, A. Robino, S. Willems, G. Pistis, N. Amin, C. Sala, L. Karssen, C. Duijn, D. Toniolo, P. Gasparini, Eur. J. Hum. Genet. 23, 1717 (2015)

[3] L. Rizzon, I. Dall'Agnol. - Brasília, DF: Embrapa Informação Tecnológica, 2009. 46 p.; il. - (Coleção Agroindústria Familiar). ISBN: 978-85-7383-477-2

[4] H. Csoma, N. Zakany, A. Capece, P. Romano, M. Sipiczki, Int. J. Food Microbiol. 140, 239 (2010)

[5] F. Comitini, M. Gobbi, P. Domizio, C. Romani, L. Lencioni, I. Mannazzu, M. Ciani, Food Microbiol. 28, 873 (2011)

[6] K. Medina, E. Boido, L. Fariña, O. Gioia, M. Gomez, M. Barquet, F. Carrau, Food Chem. 141, 2513 (2013)
[7] C. Varela, F. Sengler, M. Solomon, Food Chem. 209, 57 (2016)

[8] P. Ribéreau-Gayon, Y. Glories, A. Maujean, D. Dubourdieu. Tratado de Enologia - Quím del Vino Estab y Tratam. 2, 554 (2003)

[9] M. Martinho. Vinificações comparativas de vinhos tintos em Lagar, efeito de inoculação de leveduras e enzimas pectolíticas. (2008). 131f. Dissertação (Mestrado em Viticultura e Enologia)- Universidade Técnica de Lisboa, Lisboa, Portugal

[10] A. Lança, M. Silva. Metabolism of non-conventional wine yeasts. (2017) Dissertação de Mestrado, Universidade de Lisboa

[11] K. Chen, C. Escott, I. Loira, J. Manuel, A. Morata, W. Tesfaye, F. Calderon, J. Antonio, S. Han, S. Benito, Food Microbiol. 69, 51 (2018)

[12] M. Ciani, F. Comitini. Ann. Microbiol. 61, 25 (2011)

[13] I. Belda, E. Navascués, D. Marquina, A. Santos, F. Calderon, S. Benito, Appl. Microbiol. Biotechnol. 99, 1911 (2015)

[14] V. Breda, N. Jolly, J. Wyk, Int. J. Food Microbiol. 163 (2013)

[15] M. Sadoudi, R. Tourdot-Maréchal, S. Rousseaux, D. Steyer, J.J. Gallardo-Chacón, J. Ballester, S. Vichi, R. Guérin-Schneider, J. Caixach, H. Alexandre, Food Microbiol. 32, 243 (2012)

[16] A. Contreras, C. Hidalgo, P.A. Henschke, P.J. Chambers, C. Curtin, C. Varela, J. Appl. Environ. Microbiol. 5, 1670 (2014)

[17] D.R. Kutyna, C. Varela, P. Henschke, P. Chambers, G. Stanley, Trends food Sci. Technol. 21, 293 (2010)

[18] BRASIL. Ministério da Agricultura, Pecuária e Abastecimento. Instrução Normativa n. 14, de 08 de fevereiro de 2018. Complementação dos Padrões de Identidade e Qualidade do Vinho e Derivados da Uva e do Vinho. [online] (Brasil, 2018)

[19] L. Manfroi, A. Miele, L. Rizzon, C. Barradas. Ciênc. Tecnol. Aliment. [online] 26, 290 (2006)

[20] J. Swiegers, E. Bartowsky, P. Henschke, I. Pretorius, Aust. J. Grape Wine Res. 11, 139 (2005)

[21] D. Delanöe, C. Maillard, D. Maisondieu, El vino - del análisis a la elaboración. Editora ACRIBIA, S. A. P. 13, 233 (2003)

[22] L.A. Rizzon1, A. Miele1, G. Scopel, R. Bras, Agrociência. 17, 273 (2011)

[23] M. Bely, P. Stoeckle, I. Masneuf-Pomarede, D. Dubourdieu, Int. J. Food Microbiol. 122, 312 (2008)

[24] M. Gobbi, F. Comitini, P. Domizio, C. Romani, L. Lencioni, I. Mannazzu, M. Ciani, Food Microbiol. 33, 271 (2013)

[25] M. Azzolini, E. Tosi, M. Lorenzini, F. Finato, G. Zapparoli, World J. Microbiol. Biotechnol. 31, 277 (2015) 